\title{
SEKSUALITAS DALAM TUBUH BERGENDER
}

\author{
Khairil Anwar \\ Kajian Budaya dan Media \\ Sekolah Pascasarjana, Universitas Gadjah Mada \\ Jalan Teknika Utara, Pogung, Yogyakarta \\ No.Hp.: +6282346467918, E-mail: imajikuisland@gmail.com \\ Ratna Noviani \\ Kajian Budaya dan Media \\ Sekolah Pascasarjana, Universitas Gadjah Mada \\ Jalan Teknika Utara, Pogung, Yogyakarta \\ No.Hp.: +6281227407660,E-mail: ratna.noviani@ugm.ac.id
}

\begin{abstract}
ABSTRAK
Media populer seperti film animasi atau anime menawarkan arena kontestasi. Penelitian ini menganalisis anime berjudul Kimi no $\mathrm{Na}$ Wa (2016) sebagai sebuah arena dengan melihat beberapa adegan tertentu. Tujuannya adalah untuk melihat bagaimana subjektivitas gender dan perbedaan seksual itu dibentuk di dalam anime ini. Dengan menggunakan metode psikoanalisis feminis film dari Laura Mulvey dan Kaja Silverman, penelitian ini menyimpulkan bahwa struktur naratif dalam anime ini masih dipengaruhi oleh male bias. Hal ini berpengaruh pada bagaimana pembentukan subjektivitas gender yang menjadikan perempuan sebagai objek tatapan, sedangkan laki-laki sebagai subjek yang menatap. Selain itu, kamera yang bias gender berpotensi menciptakan tatapan yang sama dari penonton (terutama laki-laki heteroseksual) kepada karakter perempuan. Ketika Taki bertransgresi ke tubuh Mitsuha, ia melakukan bentuk fetis untuk memuaskan hasratnya pada tubuh perempuan. Akan tetapi sebaliknya, hampir tidak ada adegan yang menunjukkan secara langsung bentuk fetis yang dilakukan perempuan terhadap tubuh laki-laki. Hal ini dimungkinkan karena tubuh perempuan bisa dibicarakan secara seksual, tetapi pemikirannya dilarang untuk berpikiran seksual. Sebaliknya, tubuh laki-laki jarang untuk dibicarakan secara seksual, tetapi ia memiliki kebebasan untuk berpikir secara seksual. Pada akhirnya, struktur naratif anime ini seolah mereproduksi sistem patriarki masyarakat Jepang dalam pembentukan subjektivitas gender di sepanjang cerita.
\end{abstract}

Kata kunci: seksualitas, gender, male bias, symbolic order, transgresi

\section{ABSTRACT}

Sexuality in Gendered Bodies. Popular media such as animation or anime offer a contestation arena. This study analyzes the anime titled Kimi no Na Wa (2016) as an arena by paying attention to certain scenes. The aim is to see how gender subjectivity and sexual differences are formed in this anime. Using the film feminist psychoanalysis method from Laura Mulvey and Kaja Silverman, this study concluded that the narrative structure in this anime is still influenced by male bias. It affects the formation of gender subjectivity which makes women as the object to be looked at while men as the bearer of the looking. In addition, gender-biased cameras have the potential to create the same gaze from the audience (especially heterosexual male) towards female characters. When Taki transgresses into Mitsuha's body, he performs fetish to satisfy his desires for a woman's body. But on the contrary, there was hardly a scene directly shows the form fetish that women do to a man's body. It seems to be possible because women's bodies can be discussed sexually but their thoughts are 


\begin{abstract}
forbidden to have sexual thoughts. In contrast, a man's body is rarely talked about sexually but he has the freedom to have sexual thoughts. In the end, the narrative structure of this anime seems to reproduce the patriarchal system of Japanese society in the formation of gender subjectivity throughout the story.
\end{abstract}

Keywords: sexuality, gender, male bias, symbolic order, transgression

\section{PENDAHULUAN}

Bagaimana jika tiba-tiba kita bertukar tubuh dengan orang lain yang berlawanan jenis? Apa yang akan kita lakukan terhadap tubuh berbeda itu? Anime berjudul Kimi no $\mathrm{Na} \mathrm{Wa}(\mathrm{KnNW})$ atau Your Name (2016) karya sutradara Makoto Shinkai menceritakan dua orang remaja - Taki dan Mitsuha - yang saling bertukar tubuh atau transgresi tubuh. Anime merupakan abreviasi dari kata animation, yaitu animasi atau film kartun buatan Jepang yang awalnya diperuntukkan untuk tayangan anak kecil dan remaja (Crow, 2014). Namun, dalam dua dekade terakhir, sejak akhir tahun 1990-an tayangan kartun telah mengalami pergeseran persepsi (Ernkvist \& Ström, 2018; Tongdhamachart, 2015). Arman Dhani dalam tulisannya di Tirto.id menyatakan bahwa anime tidak lagi ekslusif dimiliki oleh anak-anak atau remaja. Kini, ceritanya juga tidak melulu tentang robot pintar atau pahlawan super yang memiliki kekuatan luar biasa (Dhani, 2016).

Makoto Shinkai dan studio ComixWave membuat anime dengan tema romansa fantasi modern (Suan, 2020; Yoshioka, 2018). Narasinya menceritakan seorang murid laki-laki bernama Taki yang tinggal di Tokyo, sedangkan tokoh utama lainnya bernama Mitsuha yang merupakan seorang murid perempuan yang tinggal di Itomori. Keduanya adalah remaja SMA-Mitsuha dan Taki-yang tidak saling mengenal satu sama lain sampai suatu hari mereka bertukar tempat dengan saling bertransgresi tubuh. Mitsuha terbangun dalam tubuh Taki, begitu pun Taki yang terbangun dalam tubuh Mitsuha. Anime ini tidak hanya menceritakan romansa percintaan di antara kedua tokoh tersebut, tetapi lebih dari itu, ada wacana yang ingin disampaikan oleh Shinkai kepada penontonnya, terutama masyarakat Jepang (Agyeiwaah, Suntikul, \& Carmen, 2019; Okamoto, 2015).

Anime sebagai sebuah film fantasi di dalamnya memuat unsur fiktif. Kendati begitu, film fiksi berada di antara abstrak dan nyata baik secara naratif ataupun sinematik (Oktaviani, 2019). Anime sebagai film fiksi bukan hanya sebagai media hiburan, tetapi juga merupakan sebuah representasi kehidupan masyarakat sosial tertentu dan dalam kurun waktu tertentu pula. Dalam film komersial, tujuan utamanya adalah meraup keuntungan ekonomi meskipun tidak bisa diabaikan bahwa terdapat sesuatu yang bersifat politis (Chow, Chui, Lai, \& Kwok, 2017; Yamamura, 2019). Ariel Heryanto dalam sebuah kuliah umum berjudul 'Historiografi Indonesia yang Rasis' menyebutkan bahwa sebuah film yang bertujuan untuk meraup keuntungan (nilai ekonomis) cenderung akan menampilkan wujud representasi atau penegasan norma yang dominan atau arus utama di masyarakat tempat media tersebut diproduksi atau didistribusikan. Bisa dikatakan teks media atau film mempunyai interelasi dengan konteks sosial tempat film tersebut diproduksi (Heryanto, 2017).

Shinkai berusaha menyampaikan kepada masyarakat Jepang, terutama kaum muda, untuk menyadari pentingnya 
melestarikan nilai-nilai tradisional melalui anime ini. Secara politis, Kimi no $\mathrm{Na} \mathrm{Wa}$ menjadi ruang baginya untuk menegaskan pentingnya menjaga tradisionalitas Jepang dengan menghadapkannya pada modernitas yang terjadi saat ini. Selain itu, ruang yang kontras antara urban dan rural dihubungkan dengan relasi gender dalam transgresi ruang dan waktu yang dialami oleh karakter utama. Tokyo digambarkan sebagai kota yang begitu megah dengan gedung-gedung pencakar langit dan kemajuan teknologinya. Tokyo menjadi representasi modernitas, sedangkan Itomori sendiri ditampilkan dalam wujud pedesaan yang menjadi representasi tradisionalitas.

Hadirnya tradisionalitas dan modernitas dalam kaitannya dengan konstruksi gender tidak ditampilkan secara terang-terangan, tetapi melalui transgresi ruang dan waktu. Dalam proses tersebut, narasi subjektivitas serta perbedaan seksual dari karakter perempuan dan laki-laki ditampilkan dan diatur sedemikian rupa dalam peristiwa transgresi ruang dan waktu. Di sini, transgresi memiliki peran kunci untuk melihat bagaimana subjek perempuan dan laki-laki itu dibentuk dan dihadirkan dalam anime. Seperti yang disampaikan oleh Karunianingsih (2016) dalam mendukung analisis diperlukan teknik sinematik yang akan mengonstuksi perempuan sebagai objek hasrat pandangan bagi orang-orang di balik produksi dan penonton.

Psikoanalisis melihat subjektivitas, seksualitas, dan ketidaksadaran sebagai titik awal untuk menunjukkan cara-cara psikoanalisis berkontribusi pada metodologi visual (Huggins, 2015; Mannay, Staples, \& Edwards, 2017). Ketiganya menunjukkan bagaimana psikoanalisis mengonseptualisasikan baik penonton maupun gambar. Dua situs ini-situs gambar dan audiensnya-adalah dua situs produksi makna yang dikaji psikoanalisis.

Subjektivitas merujuk pada karakteristik penonton yang memiliki konsekuensi untuk pendekatan psikoanalisis(Bernardi, 2015; Luyten, 2015). Pertama, subjektivitas menyaratkan pengakuan bahwa individu itu subjektif, yaitu memahami diri sendiri dan dunia melalui cara pemahaman yang kompleks dan seringkali tidak rasional.

Psikoanalisis memahami bahwa reaksi emosional seperti gambar visual tidak hanya bekerja di tingkatan sadar, tetapi juga ketidaksadaran. Pendekatan psikoanalisis memusatkan perhatian pada proses psikis dari subjektivitas dan visualitas dengan memerhatikan modalitas sosial dan konstitusi kultural karena kita belajar melihat dengan cara tertentu yang merupakan hasil dari pengalaman kita berjumpa dengan berbagai jenis gambar visual. Maka, psikoanalisis memiliki dua penekanan, yaitu meneliti subjektivitas dan perbedaan seksual.

Laura Mulvey dalam Gigi Durham, M. and Kellner (2006) memfokuskan penelitiannya pada male gaze yang mengobjektifikasi perempuan pada sinema. Mulvey mengatakan bahwa hasrat seksual yang hadir di mata penonton yang membuatnya puas berkaitan dengan kuasa yang bias gender.

Terdapat dua konsep psikoanalisis sentral-kompleks pengebirian dan tahap cermin - untuk mengeksplorasi cara kerja film naratif. Konsep male gaze ini memosisikan laki-laki sebagai si penatap (the bearer of the looking) dan perempuan sebagai objek yang ditatap (the object to be looked at) (Mulvey, 1989a). Esainya yang berjudul Visual Pleasure and Narrative Cinema menjelaskan bagaimana film populer memproduksi dan mereproduksi 
konsep male gaze tersebut. Mulvey dalam Ida (2014) mendeskripsikan pendekatannya sebagai pendekatan 'political psychoanalysis' karena teori psikoanalisis dianggap tepat untuk menunjukkan cara ketidaksadaran masyarakat patriarkal telah menstrukturkan bentuk-bentuk film. Perempuan dianggap sebagai objek dari keinginan/nafsu laki-laki (male desire) dan sebagai signifier dari 'threat of castration' atau tekanan dari kastrasi (kebiri).

Voyeurism dan fetishistic scopophilia yang terkait dengan spectatorship dapat digunakan untuk melihat narasi film. Terdapat juga dua cara memuaskan hasrat tatapan laki-laki tentang perempuan di dalam film, yaitu difetiskan dan diberi tindakan sadis (Friedlander, 2016; Mantziari, 2018).

Penggunaan dari kedua konsep ini mengasumsikan rezim scallic phallocentric, yaitu perempuan dianggap pasif atau sebagai laki-laki yang dikebiri, sedangkan laki-laki tampil aktif dan kuat, mengendalikan visual, spasial, dan temporal. Baginya, ini adalah 'cara ketidaksadaran masyarakat patriarkal menyusun bentuk film' (Mulvey, 1989b).

Kaja Silverman (1988) dalam bukunya The Acoustic Mirror mengatakan bahwa suara perempuan selalu terikat dengan tontonan tubuh, disajikan sebagai 'thick with body' seperti menangis, terengah-engah, berteriak, mengoceh, berguman dengan menyelaraskan antara suara dan gambar. Namun, sayangnya perempuan hanya diberi sedikit atau bahkan tidak ada suara otoritatif dalam narasi cerita. Ucapan perempuan dalam film kerap kali dicirikan tidak dapat dipercaya, tidak diandalkan, kegagalan, menghalangi, atau ungkapan persetujuan (Chaudhuri, 2006).

Silverman mengadaptasikan konsep cermin Lacan pada film dan menyimpulkan bahwa subjek perempuan dalam sinema dibuat untuk memikul beban kekurangan yang dimiliki oleh subjek laki-laki dan perempuan. Laki-laki mempertahankan fantasi diri yang sempurna dengan memproyeksikan kekurangan dirinya pada perempuan. Selain itu, di dalam film tidak hanya tubuh perempuan yang dibuat kehilangan atau kekurangan, tetapi juga suaranya (Chaudhuri, 2006).

Hall (1997) mengatakan bahwa representasi adalah proses produksi dan pertukaran makna, baik itu antara manusia atau antar-budaya dengan menggunakan media berupa gambar, simbol atau bahasa. Di dalam sinema, Hall mengatakan bahwa film merupakan sebuah sistem representasi di mana praktik-praktik pemaknaan dilakukan.

\section{Barker (2014) dalam Kamus Kajian}

Budaya menyebutkan bahwa praktik-praktik penandaan tersebut tampaknya menggambarkan objek atau praktik yang terjadi di dunia nyata. Ia menekankan pada kata 'tampaknya' karena tidak sepenuhnya seperti itu. Representasi bukanlah refleksi murni dari kenyataan namun merupakan konstruksi kultural yang bisa jadi sangat berbeda dengan apa yang tampak. Proses representasi tidak terlepas dari unsur kekuasaan melalui proses seleksi dan organisasi dalam pembentukan representasi itu sendiri.

Kekuatan representasi terletak pada kemampuannya "menghidupkan" sejumlah pengetahuan dan "mematikan" pandangan lain. Hall menyebut keadaan ini sebagai politik representasi di mana terjadi kesewenangan peniadaan sekaligus menciptakan kesediaan hidup dengan perbedaan. Jadi, politik representasi menyelidiki lebih jauh ke dalam relasi-relasi kekuasaan yang hadir dalam representasi dan secara bersamaan melakukan dekonstruksi (Cushman, 2015). 
Hall (1997) menegaskan poin utamanya, bahwa makna tidak ada di dalam benda-benda atau di dunia. Makna itu dibangun, dikonstruksi, atau diproduksi. Hal tersebut merupakan hasil dari praktik penandaan - suatu praktik yang menghasilkan makna-yang membuat segala sesuatu menjadi berarti. Oleh karena itu, konsep (pikiran) dan tanda (bahasa) merupakan alat untuk memproduksi dan mengonstruksi makna. Hall menyarankan menggunakan pendekatan konstruksionis dibandingkan intensional ataupun reflektif.

Pada konteks gender, representasi itu menghadirkan sesuatu yang absen pada subjek. Perempuan atau laki-laki hadir dan memunculkan perspektif baru untuk menampilkan serta memberi posisi subjek, bukan mereproduksi apa yang absen. Bahasa menjadi alat untuk menghadirkan yang absen. Namun, Buikema yang mengutip Bakhtin (1982) mengatakan bahwa "the word does not forget its own path". Oleh karena itu, bahasa berpotensi menghadirkan kembali ingataningatan tentang konteks sebuah kata atau bahasa yang ada di masa lalu. Setiap teks atau tanda yang digunakan memiliki keterkaitan dengan sebelumnya atau konteks lain yang memiliki makna konotasi sehingga kita tidak tahu bahwa sebuah teks atau tanda berbicara lebih dari yang kita sadari (Buikema, 2009).

\section{METODE PENELITIAN}

Rose (2006) mengatakan bahwa psikoanalisis adalah metode yang bekerja dengan visualisasi atau gambar. Anime sebagai rangkaian gambar bergerak menghadirkan citracitra visual. Dalam tampilannya, anime Kimi no $\mathrm{Na} \mathrm{Wa}$ sebagai korpus penelitian menghadirkan visualisasi yang menunjukkan subjektivitas gender dan perbedaan seksual.
Psikoanalisis pada dasarnya menolak anggapan subjek dan seksualitas yang sudah tetap dan terberi sehingga ia menyelidiki proses pembentukan subjektivitas dengan berfokus pada subjektivitas yang bergender. Metode psikoanalisis digunakan untuk menginterpretasi materi visual yang ada untuk menyelidiki bagaimana subjektivitas itu dibentuk dalam tatanan simbolik.

Psikoanalisis sebagai metode tidak seperti analisis konten atau semiotika, tetapi berangkat dari konsep dan bagaimana kemudian diartikulasikan ke dalam struktur naratif film (Rose, 2006). Teori psikoanalisis merupakan teori yang berusaha untuk menjelaskan hakikat dan perkembangan kepribadian manusia (Syawal and Helaluddin, 2018).

Dalam konteks riset ini akan digunakan konsep male gaze dari Laura Mulvey, female voice dari Kaja Silverman, dan bagaimana konsep-konsep itu diartikulasikan di dalam anime Kimi no Na Wa.

\section{PEMBAHASAN}

\section{Laki-Laki dalam Ketubuhan Perempuan}

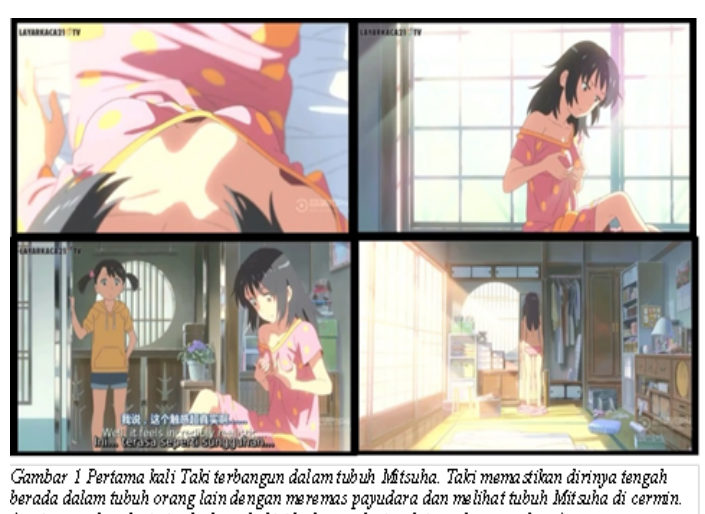

B. (urutan gambar dari atas ke bawah, kini ke kanan dari sudut pandang pembaca)

Pengalaman transgresi tubuh dan kesenangan seksual tergambarkan dalam struktur naratif berupa visual dalam anime. Keduanya melakukan identifikasi diri pada tubuh yang ditempatinya terutama meraba 
bagian tubuh yang vital. Transgresi merupakan pelanggaran terhadap tabu (Darmawan et al, 2016). Taki meraba tubuh Mitsuha di bagian payudara untuk memastikan bahwa dia berada dalam tubuh yang berbeda (lihat gambar 1). Setelah itu, lamat-lamat dia memandang seisi kamarnya untuk mengafirmasi bahwa dirinya tidak berada di tubuh yang seharusnya.

Berulang kali adegan tersebut terjadi hingga terbiasa dengan transgresi tubuh yang terjadi. Selain banyaknya jumlah scene yang menunjukkan adegan tersebut, terlihat juga ekpresi yang ditunjukkan ketika melakukan adegan tersebut. Scene Taki meremas payudara atau ketubuhan perempuan terhitung sebanyak empat kali. Melalui ekspresi yang ditangkap dari gambar, Taki awalnya ditunjukkan bingung ketika kali pertama mengalami transgresi tubuh, tetapi kemudian tampak menikmati adegan meraba bagian tertentu dari tubuh Mitsuha. Kenikmatan yang diperoleh Taki di sini bisa disebut sebagai bentuk scopophilia. Namun, scopophilia juga terkait dengan spectatorship sehingga tidak hanya Taki yang digambarkan mendapatkan kepuasan, tetapi narasinya juga memfungsikan elemen-elemen naratifnya untuk mengarahkan posisi-posisi spectator agar memperoleh kepuasan.

Dalam kajiannya, Mulvey menyebutkan bahwa scopopilhia yang diambil dari Freud berbicara tentang sexual pleasure yang diperoleh lewat menonton dan melihat. Dalam konteks film, Mulvey mengatakan ada dua cara untuk melihat narasi film, yaitu voyeurism dan fetishistic scopophilia. Voyeurism dimaksudkan untuk melihat relasionalitas antara maskulinitas dan femininitas yang dibangun pada sebuah film. Voyeurism berkaitan bagaimana hasrat melihat tersebut dilakukan tanpa sepengetahuan orang yang dilihat. Kenikmatan yang terbentuk adalah kesenangan mengintip tanpa ketahuan. Fetishistic scopophilia melihat kehadiran perempuan hanya sebagai objek tampilan atau diobjektivikasi sehingga keberadaannya merupakan hasil dari praktik pencitraan. Pada kebanyakan film, perempuan sering ditampilkan sebagai objek tatapan dengan mengaitkannya pada persoalan ketubuhan (Mulvey, 1989b).

Pada gambar 1 bagian kiri atas, kamera mengambil sudut pandang Taki dalam tubuh Mitsuha yang melihat payudara dari arah atas. Di dalam film, teknik sinematik acapkali digunakan untuk menunjukkan hasrat memandang lakilaki terhadap perempuan (Karunianingsih, 2016). Kamera seolah-olah merupakan tatapan mata karakter utama (Taki) yang melihat payudara dan mengarahkan penonton (terutama laki-laki heteroseksual) mengidentifikasi diri mereka sebagai Taki. Selain itu, kamera juga melakukan teknik pengambilan gambar close up di bagian payudara untuk menciptakan kedekatan dengan penonton agar fokus di bagian itu saja. Close up membuat penonton tidak memiliki kesempatan untuk mengalihkan pandangan ke hal lain yang bisa mengganggu sesuatu yang ingin ditonjolkan.

Ketika kamera bergerak ke samping dengan pembingkaian gambar secara medium shot untuk memperlihatkan suasana kamar seperti pada gambar kanan atas, penonton tetap akan berfokus pada payudara Mitsuha. Hal ini dimungkinkan karena ada aktivitas yang terjadi di titik tersebut, yaitu gerakan tangan yang meremas payudara sedangkan background gambar atau situasi kamar dalam keadaan diam tanpa ada gerakan atau pasif. Selain itu, kontras warna pakaian yang mencolok dengan pencahayaan yang berasal dari jendela pada background membantu penonton memfokuskan pandangan pada aktivitas tubuh Mitsuha. 
Adegan Taki yang meremas payudara Mitsuhaberulang kali dilakukanhingga akhirnya adik Mitsuha (Yotsuha) menghampirinya di kamar tidurnya seperti pada gambar kiri bawah, ia tetap saja tidak melepaskan tangan dari payudara tersebut. Kehadiran karakter lain tidak sepenuhnya membuat kita berfokus padanya-hanya sepintas untuk melihat keberadaan karakter baru dalam layar yang ditangkap kamera. Pencahayaan berperan penting dalam membantu penonton tetap fokus pada aktivitas di tubuh Mitsuha. Pencahayaan yang menerpa tubuh Mitsuha tampak lebih terang karena pancaran sinar matahari yang menembus jendela kamar tidurnya membuat penonton dengan mudah kembali terfokus pada aktivitas Taki terhadap tubuh Mitsuha.

Begitu Yotsuha pergi, ia berdiri lalu melepas pakaian yang dikenakannya dan bercermin melihat seluruh tubuh Mitsuha yang hanya berbalut celana dalam. Sebelum gambar pada kanan bawah tersebut kamera melakukan close up pada bagian pantat lalu beralih ke mode long shot untuk melihat keseluruhan tubuh Mitsuha dari kaki sampai kepala. Bentuk male gaze yang dilakukan oleh kamera bisa dilihat dari close up di bagian pantat mengarahkan penonton melihat secara detail bagian tubuh perempuan yang dianggap bisa memberikan efek seksual. Dalam konteks ini, pengambilan gambar secara close up menunjukkan tidak hanya karakter laki-laki yang aktif menatap, tetapi posisi kamera yang diposisikan sebagai laki-laki juga aktif menatap.

Aktivitas yang dilakukan karakter laki-laki terhadap karakter perempuan di sini bisa dikatakan mereduksi tubuh perempuan hanya pada urusan seksual. Pada saat mereka mengalami transgresi tubuh, keduanya dibuat mengalami pemisahan antara body dan mind mereka sehingga mereka tidak lagi memiliki kendali atas tubuhnya. Baik Taki maupun Mitsuha tidak memiliki otoritas terhadap tubuhnya karena kesadaran mereka tidak lagi berada di tubuhnya, tetapi mereka kemudian memiliki kendali atas tubuh yang berbeda. Taki memiliki kendali terhadap tubuh Mitsuha dan sebaliknya. Proses ini dilanggengkan oleh transgresi ruang (tubuh) yang terjadi antara keduanya untuk mewajarkan kehilangan kesadaran yang terjadi pada tubuh mereka. Dalam penyajiannya, tubuh perempuan digambarkan menjadi objek yang difetiskan (fetishistic schopophilia), tubuh Mitsuha menjadi objek hasrat seksual Taki. Bentukbentuk fetis seperti menampakkan bagian tubuh vital perempuan, menyentuh bagian vital seperti payudara dibantu dengan cara kerja kamera yang dipengaruhi perspektif male bias.

Adegan-adegan fetis tersebut terkait dengan konteks kultural masyarakat Jepang yang masih menganut paham patriarki meskipun mereka telah berusaha meninggalkan hal tersebut sejak pasca-Perang Dunia II (PD II). Laki-laki tetap menjadi symbolic order yang mengendalikan aturan atau norma dalam masyarakat karena laki-laki adalah kata lain dari norma itu sendiri. Perempuan, seperti yang dikatakan Mulvey kemudian dianggap sebagai bentuk lack dari laki-laki. Dalih ini kemudian dijadikan sarana objektivikasi terhadap sosok perempuan karena dianggap memiliki potensi untuk mengebiri atau memberikan ancaman kepada pemilik norma, laki-laki.

Ketidakberimbangan yang terjadi dalam penayangannya menegaskan bahwa anime ini bekerja dalam struktur naratif yang bias gender. Laki-laki merupakan subjek yang harus dipuaskan karena posisinya sebagai tatanan simbolik dalam masyarakat. Perlakukan 
Taki ini mengindikasikan apa yang disebut oleh Mulvey sebagai voyeurism, bahwa tanpa sepengetahuan Mitsuha, ia tetap mengulangi perbuatannya meremas payudara Mitsuha. Keinginan Taki untuk melakukan hal tersebut merupakan representasi dari hasrat seksual lakilaki terhadap tubuh perempuan. Kesadaran akan hasrat tersebut didorong ke arah ketidaksadaran karena adanya norma-norma yang menganggap tabu perilaku seperti itu. Anggapan tabu tersebut menjadi "hilang" atau "terwajarkan" ketika transgresi tubuh terjadi sehingga Taki dapat terus-menerus mengoperasi ketubuhan Mitsuha tanpa merasa risi.

Jika merujuk pada produksi kultural dan representasi, media hal ini bisa disebut symbolic annihilation, yaitu proses mengabaikan atau memarjinalkan perempuan ke dalam stereotipe yang didasarkan pada daya tarik seksual atau kerja domestik. Tuchman dalam Strinati, D. and Mukhid (2003) mengatakan secara ringkas perempuan dianggap tidak ada, diremehkan, atau secara simbolis dianihilasikan. Selain tubuhnya yang dianihilasikan, Silverman dalam Chaudhuri (2006) mengatakan bahwa dalam film bukan hanya tubuh perempuan yang dibuat merasa kehilangan, tetapi begitu pula suaranya. Mereka jarang sekali mendapatkan waktu untuk narasi panjang. Suara perempuan selalu dihubungkan dengan tubuhnya, sedangkan laki-laki terlepas dengan unsur ketubuhannya.

Ketika diberi ruang untuk bicara, ucapan perempuan sering dicirikan tidak dapat dipercaya, tidak penting, tidak diandalkan sehingga mudah untuk mengabaikan apa yang dikatakan. Dalam KnNW, aturan yang dibuat Mitsuha dianggap bukanlah hal yang penting sehingga tidak masalah untuk dilanggar. Hal ini mengindikasikan bahwa meskipun dalam keseluruhan film, Mitsuha sebagai pemeran utama perempuan diberi banyak ruang untuk bicara, suaranya tidaklah merupakan narasi yang penting dan cenderung bergantung pada narasi yang dibuat oleh pemeran utama laki-laki. Lakilaki ditunjukkan menguasai ucapan, pendengaran, dan penglihatan. Dengan kata lain, perempuan tidak memiliki suara yang otoritatif dibandingkan laki-laki dalam keseluruhan narasi cerita.

Kesenangan seksual pada tubuh perempuan tidak lagi hanya dinikmati dari proses "mengintip" (voyeurism), tetapi transgresi tubuh di sini memungkinkan laki-laki bisa melakukan kesenangan seksual terhadap tubuh perempuan secara terang-terangan tanpa merasa risi. Sebenarnya dalam narasi anime ini, Taki masih melakukannya tanpa sepengetahuan Mitsuha, tetapi ada orang lain (Yotsuha dan neneknya) yang mengetahui hal tersebut. Walaupun begitu, Taki tetap tidak risih bahkan ia tidak peduli ketika Yotsuha menyindir perbuatannya yang tiap pagi meremas payudara.

\section{Perempuan dalam Ketubuhan Laki-Laki}

"Aku benci desa ini. Aku benci kehidupan ini. Kumohon jadikan aku cowok Tokyo tampan di kehidupan selanjutnya!" teriak Mitsuha di bawah torii dan disaksikan Yotsuha. Narasi KnNW ini bisa dimulai dari harapan Mitsuha untuk menjadi laki-laki dan tinggal di Tokyo jika diberi kesempatan bereinkarnasi. Keinginan Mitsuha ini diungkapkan sesaat setelah selesai melakukan prosesi pembuatan kuchikamisake (jenis sake tertua di Jepang).

Meskipun begitu, keinginan yang diteriakkannya itu bukanlah penyebab Mitsuha mengalami transgresi tubuh. Dalam narasi anime, nenek Mitsuha menjelaskan bahwa secara turun-temurun sosok perempuan di dalam keluarganya mengalami transgresi tubuh ketika beranjak remaja. 
Dalam kerangka sosial kultural Jepang yang menganut sistem patriarki, perempuan acapkali didudukkan sebagai objek sehingga proses transgresi ke tubuh laki-laki ini bisa dilihat sebagai upaya menjadikan perempuan sebagai subjek. Namun, keinginan perempuan untuk menjadi subjek bukanlah hal yang baru.

Jika merujuk pada pernyataan nenek Mitsuha dalam narasi, sebelum Mitsuha, nenek dan ibu Mitsuha juga pernah mengalami hal tersebut ketika beranjak remaja. Hal ini bisa dilihat bahwa keinginan perempuan menjadi subjek, menjadi maju, dan modern sudah terjadi sejak lama dan terus-menerus direproduksi dari generasi ke generasi.

Fase remaja yang dikatakan nenek Mitsuha adalah fase antara kanak-kanak dan dewasa, yaitu ketika seseorang mulai memiliki kendali akan kesadarannya. Pada fase ini, perempuan mengalami bentuk fantasi akan lack yang selama ini dialami olehnya yang direpresentasikan pada anggota keluarga Mitsuha di KnNW sehingga ia ingin menjadi sesuatu yang utuh atau sebagai subjek.

Lalu bagaimana Mitsuha menggunakan "kelaki-lakiannya" atau tubuh laki-laki yang ditempatinya ketika ia mengalami transgresi tubuh?

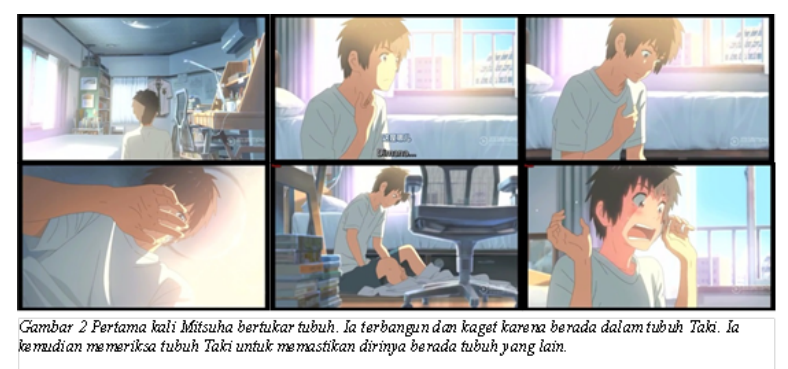

Dalam anime ini, perilaku seksual pada tubuh tidak hanya terjadi pada tubuh perempuan. Mitsuha dalam anime ini juga melakukan hal tersebut pada tubuh laki-laki. Meskipun begitu, tindakan tersebut tidak sesering seperti perlakuan pada tubuh perempuan. Mitsuha memeriksa penis yang berada di selangkangan tubuh Taki untuk memastikan peristiwa transgresi tubuh yang terjadi pada dirinya. Seperti Taki, Mitsuha juga memandang seisi kamar secara saksama untuk memastikan keberadaanya. Jika pada scene Taki meremas payudara terhitung sebanyak empat kali, scene Mitsuha memegang penis hanya dua kali. Namun, kedua scene tersebut juga tidak secara langsung menyorot adegan ketika tangan memegang penis seperti ketika tangan memegang payudara. Seketika kamera mengalihkan ke objek tubuh yang lain seperti menyorot ke wajah untuk menunjukkan ekspresi. Mitsuha yang berada dalam tubuh Taki digambarkan dengan ekspresi kaget lalu sesaat kemudian menjadi malu yang bisa dilihat dari rona merah di pipinya. Perubahan sorotan kamera dari adegan memegang penis ke ekspresi wajah dilanggengkan oleh cara kerja kamera yang male bias (lihat gambar 2).

Jika merujuk pada konsep Freud tentang Oedipus complex, pada tingkatan fase phallic, pusat kenikmatan adalah alat kelamin. Perempuan mulai menyadari dirinya tidak memiliki phallus sebagai sesuatu yang lebih hebat dari ketubuhannya. Keinginan akan phallus ini membuat perempuan menghasrati bapaknya, tetapi keinginan incest itu dianggap tabu sehingga mencari subtitusi phallus. Ketika masalah phallic tidak terselesaikan dengan baik, anak akan merasakan sifat phallic akibat timbulnya rasa malu dan kehilangan kontrol akan dirinya. Mitsuha yang merasa kaget mendapati phallus pada tubuhyang ditempatinya menunjukkan bahwa struktur naratif anime ini tidak menghendaki hal tersebut.

Dalam konteks pembahasan ini, akan digunakan istilah phallus - agar tidak terjebak 
pada fisiologis - yang merupakan simbolisasi dari kelaki-lakian atau pembeda antara laki-laki dan perempuan. Lacan mengatakan phallus sebagai symbolic order dalam masyarakat yang patriarki. Adegan ketika kali pertama Mitsuha berada di dalam tubuh milik Taki, ketika ia terbangun, Mitsuha heran dengan apa yang dilihatnya lalu mempertanyakan keberadaannya pada dirinya sendiri. Ia kaget karena suara yang keluar bukanlah suaranya. Ia kemudian memeriksa jakun Taki seperti gambar bagian tengah atas. Gambar medium shot ini membantu kita melihat apa yang sedang dilakukan Mitsuha terhadap tubuh Taki. Begitu pun dengan gambar kanan atas, Mitsuha lalu mengalihkan tangan ke arah dada. Sebagai catatan, jakun dan dada dalam ketubuhan lakilaki pada umumnya bukanlah bagian tubuh yang menimbulkan hasrat seksual berbeda dengan dada perempuan.

Secara umum, satu-satunya alat vital yang secara seksual bisa membangkitkan hasrat yang ada di tubuh laki-laki adalah bagian penis. Pencahayaan yang berasal dari sinar matahari yang menembus jendela kamar memberikan fokus pada ekspresi wajah yang tampak kebingungan. Ekspresi bingung juga ditunjukkan oleh Taki meskipun hanya sesaat ketika kali pertama meremas payudara, sedangkan ekspresi bingung terus-menerus dijumpai di diri Mitsuha.

Sesuatu yang menarik bisa dilihat dari gambar kiri bawah, ketika Mitsuha merasa terdapat benda asing di bagian selangkangan dari tubuhnya. Ia kemudian memeriksa bagian tersebut. Sudut pandang kamera dalam adegan ini berada di posisi low angle dari arah penis dengan mode close up ke wajah Mitsuha yang sedang bertrasgresi ke tubuh Taki. Jika kembali ke gambar 1 pada bagian kiri atas, kamera mewakili mata karakter laki-laki untuk melihat payudara milik karakter perempuan. Hal yang sama juga bisa dikatakan berlaku pada gambar ini. Jika penis merupakan alat kelamin untuk menunjukkan kelaki-lakian seseorang, kamera juga meminjam mata karakter laki-laki (penis) untuk melihat ke arah wajah yang karakter perempuan (wajah Taki) yang juga ditutupi oleh tangan. Mulvey dalam Gigi Durham dan Kellner (2006) menyebut pemandangan ini dimungkinkan terjadi karena konsep male gaze yang memosisikan laki-laki sebagai si penatap (the bearer of the looking) dan perempuan sebagai objek yang ditatap (the object to be looked at).

Gambar tengah bawah menunjukkan kejadian ketika Mitsuha memegang penis Taki. Sudut pandang kamera kemudian berubah ke metode long shot dari sudut pandang penonton. Pembingkaian gambar yang dilakukan oleh kamera pada tubuh Taki tidak menunjukkan bagaimana tangan tersebut menyentuh penis. Peristiwa tersebut secara tidak langsung telah disensor dengan keberadaan paha kanan Taki yang melindungi adegan tangan memegang penis. Selain itu, keberadaan kursi yang mengambil setengah ruang dari pembingkaian kamera untuk meminimalisasi fokus dalam adegan tersebut.

Hal ini dimungkinkan terjadi karena kamera bekerja dengan cara pandang laki-laki sehingga melindungi bagian yang vital dari tubuh laki-laki agar tidak terekspos. Struktur naratif film ini dikendalikan oleh castration anxiety sehingga adegan tangan memegang phallus tidak dimunculkan atau disensor oleh kamera. Hal ini dibenarkan oleh Mulvey yang mengatakan bahwa laki-laki sebagai pemilik norma (symbolic order) dalam masyarakat patriarki kerap merasa terancam oleh 
keberadaan perempuan sehingga perlakuan fetis dilakukan untuk memastikan perempuan tidak bisa lebih hebat dari laki-laki.

Gambar di bagian kanan bawah menunjukkan ekspresi Mitsuha setelah memegang penis milik Taki. Gambar medium close up disertai pencahayaan pada sebagian wajah membuat penonton berfokus pada ekspresi Mitsuha. Ia ditunjukkan kaget dengan setengah berteriak yang tergambar pada mulut yang terbuka, mata yang melotot, dan kedua tangan terangkat sejajar wajahnya. Ekspresi seperti ini tidak ditemukan dalam adegan ketika Taki kali pertama berada di tubuh Mitsuha kendati ia dilihat oleh orang lain, Yotsuha. Ekspresi kaget ini juga merupakan bentuk fetis yang dilakukan oleh film untuk memberikan kepuasan kepada penonton terutama laki-laki heteroseksual dalam mengekspos ekspresi perempuan.

Jika merujuk pada Silverman, gambar ini bisa dibaca sebagai bentuk pengebirian simbolik kepada perempuan. Silverman dalam Chaudhuri (2006) mengatakan bahwa dalam sinema, subjek perempuan dibuat memikul beban kekurangan yang dimiliki subjek lakilaki dan perempuan. Laki-laki menyadari ada yang kurang dalam dirinya dan ia tidak bisa menanggung hal tersebut sehingga memproyeksikan kekurangan tersebut terhadap perempuan.

Ekspresi kaget dan malu di sini bisa dibaca sebagai sebuah kelemahan bagi laki-laki dalam masyarakat patriarki. Laki-laki dianggap memiliki mental yang kuat, tidak kaget apalagi malu untuk hal-hal yang berhubungan seksual karena pemikirannya dibebaskan berbicara secara seksual. Pada KnNW, Taki yang tidak sanggup menanggung beban menjadi malu dan kaget kemudian memproyeksikan hal tersebut kepada Mitsuha yang bertransgresi ke tubuhnya. Silverman menyebutkan bahwa upaya ini dilakukan laki-laki untuk mempertahankan fantasi akan diri yang sempurna, diri yang tidak merasa malu atau kaget.

Jika Mitsuha melarang Taki untuk berlaku sembarang terhadap tubuhnya, lain halnya dengan aturan yang dibuat Taki kepada Mitsuha. Hal yang dilarang berhubungan dengan gaya hidup bukan persoalan ketubuhan, yaitu jangan boros, jangan pakai dialek, dan jangan telat. Jangan boros untuk mengkritik gaya hidup Mitsuha sebagai perempuan yang suka membelanjakan uangnya untuk hal yang tidak penting yang memiliki interealsi dengan konteks kultural yang menstereotipekan perempuan dengan budaya konsumtif. Larangan penggunaan dialek (desa) untuk menegaskan keterkaitan laki-laki dengan kota atau modernitas, sedangkan perempuan dengan tradisionalitas. Taki juga mengingatkan Mitsuha agar tidak telat kerja. Larangan kepada Mitsuha merupakan bentuk devaluasi atau keraguan akan kemampuan perempuan sehingga Taki merasa perlu memberikan catatan sebagai bentuk ketidakpercayaan akan Mitsuha.

Aturan-aturan yang mereka buat bisa diselidiki dengan melihat kaitannya dengan konteks kultural yang telah ada. Secara kultural, tubuh perempuan seringkali dibicarakan, sedangkan pikirannya dianggap suci atau dengan kata lain dia dilarang untuk berpikiran seksual. Lain halnya dengan lakilaki, secara seksual persoalan tubuhnya jarang dibincangkan ataupun dieksplorasi, tetapi mereka berhak berpikiran secara seksual.

Otoritas ketubuhan laki-laki yang didapatkan Mitsuha setelah mengalami transgresi tubuh rupanya tidak serta-merta membuatnya jadi subjek. Kesadarannya masih 
membuat dia terperangkap pada keadaan yang menempatkan dirinya sebagai objek ketimbang sebagai subjek. Ia bahkan enggan melakukan proses fetis atau voyeurism terhadap tubuh lakilaki yang diatur melalui struktur naratif yang membangun anime ini.

Dalam narasi KnNW, bisa dilihat juga pembagian durasi ceritanya yang cukup seimbang dengan menggunakan dua sudut pandang dari Mitsuha dan Taki. Namun, karakter utama laki-laki lebih berperan sebagai pengendali dan penentu alur cerita atau berlaku sebagai symbolic order. Suara-suara Taki menjadi otoritatif dibanding suara Mitsuha meskipun keduanya menjadi narator dalam cerita ini. Kata Mulvey, hal tersebut bisa dibaca sebagai representasi kekuasaan yang mengatur dan menjadikan perempuan sebagai objek tontonan atau difetiskan (Mulvey, 1989b).

Selain tindakan fetis, seperti kata Mulvey, perempuan juga sering diberi tindakan sadis atau dihukum. Tindakan tersebut dilakukan jika ternyata kekuatan perempuan sudah sampai pada tahapan siap untuk mengebiri laki-laki. Dalam anime ini, tindakan sadis diberikan kepada Mitsuha karena ia telah meraba bagian phallus di tubuh laki-laki sehingga patut untuk diberikan hukuman. Perilaku sadis juga disematkan kepada Mitsuha berupa bencana dengan jatuhnya pecahan meteor yang menimpa Itomori sehingga seluruh warga termasuk dirinya meregang nyawa dalam kejadian itu.

Dalam KnNW, kelimpahan porsi visual yang didapatkan oleh Taki memungkinkan ia memiliki ruang yang besar dalam narasi film. Seperti dongeng-dongeng cerita kanak-kanak, si perempuan yang tidak berdaya membutuhkan pertolongan laki-laki untuk menyelamatkan hidupnya. KnNW mereproduksi hal tersebut dengan menjadikan Taki sebagai sosok pahlawan yang bisa menyelamatkan Mitsuha sebagai bentuk representasi laki-laki menyelamatkan perempuan. Reproduksi konteks kultural ini menegaskan seberapa pun perempuan berusaha, mereka tidak akan mampu tanpa bantuan laki-laki.

Pada akhirnya, Mitsuha tidak menggunakan otoritas tubuh laki-laki yang ditempatinya padahal ia diberi ruang untuk menjadi subjek. Jika dalam masyarakat patriarki tubuh merupakan poin penting yang menentukan apakah seseorang berhak menyandang predikat maskulin atau feminin, dalam kasus KnNW hal tersebut tidak terjadi. Mitsuha tetap membawa kesadaran femininnya ke dalam tubuh Taki yang berarti ia juga tetap menempatkan dirinya sebagai objek ketimbang subjek. Begitu pun dengan Taki yang membawa kesadaran maskulinnya ke dalam tubuh Mitsuha dan menempatkan dirinya sebagai subjek. Ketika Mitsuha dalam tubuh Taki berkumpul bersama teman sekolah Taki, ia cenderung mengikuti keinginan teman-temannya dibanding ketika Taki berada di tubuhnya sendiri yang memiliki kehendak dalam memilih. Otoritas ketubuhan yang diperoleh Mitsuha setelah mengalami transgresi tubuh seolah hanya sebatas berganti tubuh tanpa memanfaatkan potensi dari symbolic order tubuh yang ditempatinya.

\section{SIMPULAN}

Ketika mengalami transgresi tubuh dan saling bertukar ruang, laki-laki dan perempuan sama-sama memiliki kendali penuh atas tubuh yang ditempatinya, tetapi sekaligus kehilangan kontrol akan tubuh mereka. Namun, bentuk kendali atas tubuh yang lain ini berbeda antara kesadaran perempuan dan laki-laki. Pengalaman dalam tubuh yang berbeda ditunjukkan dalam beberapa visualisasi adegan di sepanjang anime. Laki-laki dalam ketubuhan perempuan 
memiliki kendali untuk melakukan objektivikasi dan mengeksplorasi tubuh perempuan. Bentukbentuk voyeurism dan fetishistic scopophilia dilakukan oleh karakter laki-laki pada zonazona erotis tubuh perempuan yang bisa menimbulkan hasrat seksual. Taki yang awalnya kaget ketika menyentuh dan memandang zona erotis tersebut berubah menikmati setiap aktivitas yang dilakukan pada tubuh Mitsuha. Selain karakter utama laki-laki, male gaze juga dilakukan oleh kamera sehingga mengarahkan penonton (terutama laki-laki heteroseksual) untuk memandang perempuan sebagai objek tatapan seksual.

Kondisi berbeda ditunjukkan ketika perempuan berada di tubuh laki-laki, adegan yang mengeksplorasi tubuh laki-laki lebih sedikit dibanding yang terjadi pada tubuh perempuan. Kalau pun ada, kamera tidak menunjukkan adegan ketika melakukan sentuhan pada zona-zona erotis tubuh laki-laki. Ekspresi Mitsuha yang awalnya kaget berubah menjadi malu karena mengetahui ada phallus pada tubuh yang ditempatinya. Ekspresi ini dimungkinkan terjadi karena struktur naratif film yang berkaitan dengan konteks kultural masyarakat Jepang yang patriarki. Struktur naratif yang male bias ini memosisikan lakilaki sebagai symbolic order dalam narasi film.

Naratif film kemudian dibangun dengan castration anxiety sehingga adegan ketika meraba penis tidak ditunjukkan. Selain itu, phallus sebagai simbolisasi 'kelaki-lakian' menghalangi hasrat perempuan terhadap benda di selangkangan tubuh laki-laki tersebut. Ia merasa hal tersebut adalah sesuatu yang tabu dan dibuat takut dengan hukuman dari ayah yang akan menimpanya jika melanggar normanorma sosial yang ada. Jadi, tubuh perempuan sering dibicarakan secara seksual, tetapi pikirannya dilarang untuk berpikir seksual. Sementara itu, laki-laki tubuhnya jarang dibicarakan secara seksual, tetapi dibiarkan berpikiran secara seksual.

Segregasi antara feminin dan maskulin juga bisa dilihat dari catatan yang mereka buat saat mengalami transgresi tubuh. Catatan Mitsuha kepada Taki berisi seputar larangan terhadap ketubuhannya, sedangkan sebaliknya berisi larangan yang masih memiliki kaitan dengan stereotipikal terhadap perempuan. Hal ini menunjukkan bentuk symbolic annihilation yang mengabaikan perempuan ke dalam stereotipe tentang daya tarik seksual dan kerja domestik semata. Larangan yang diberikan terhadap laki-laki pun diabaikan, sedangkan larangan kepada perempuan dijalankan.

Secara keseluruhan, struktur naratif anime ini menempatkan perempuan sebagai objek tatapan dan laki-laki sebagai subjek yang menatap. Bentuk fetis terhadap sosok perempuan dilakukan di sepanjang cerita baik secara visual maupun dialog. Selain itu, tindakan sadis atau hukuman juga diberikan kepada perempuan yang memiliki keinginan untuk menjadi subjek, modern, atau setara dengan laki-laki. Hukuman diberikan kepada karakter perempuan, sedangkan karakter laki-laki diberi tugas menjadi pahlawan yang menyelamatkan perempuan dari hukuman yang dialaminya. Kesimpulannya, struktur naratif anime KnNW masih dikendalikan oleh logika yang male bias.

\section{KEPUSTAKAAN}

Agyeiwaah, E., Suntikul, W., \& Carmen, L. Y. S. (2019). 'Cool Japan': Anime, soft power and Hong Kong generation $\mathrm{Y}$ travel to Japan. Journal of China Tourism Research, 15(2), 127-148. 
Barker, C. (2014). Kamus Kajian Budaya. Yogyakarta: Kanisius.

Bernardi, R. (2015). What kind of discipline is psychoanalysis? The International Journal of Psychoanalysis, 96(3), 731-754.

Buikema, R. (2009). The arena of imaginings: Sarah Bartmann and the ethics of representation. In Doing gender in media, art and culture. New York: Routledge.

Chaudhuri, S. (2006). Feminist Film Theorists. New York: Routledge.

Chow, B. W.-Y., Chui, B. H.-T., Lai, M. W.-C., \& Kwok, S. Y. C. L. (2017). Differential influences of parental home literacy practices and anxiety in English as a foreign language on Chinese children's English development. International Journal of Bilingual Education and Bilingualism, 20(6), 625-637.

Crow, J. (2014). Early Japanese Animations: The Origins of Anime (1917-1931), openculture.com.

Cushman, P. (2015). Relational psychoanalysis as political resistance. Contemporary Psychoanalysis, 51(3), 423-459.

Darmawan, A., Priyatna, A. and Saidi, A. I. (2016). Unsur-Unsur Gotik dalam Novel. Metasastra, 8(2), 161-178. https://doi. org/10.26610/metasastra.2015.v8i2.161178.

Dhani, A. (2016). Tangan Midas Sutradara Anime Makoto Shinkai, tirto.id.

Ernkvist, M., \& Ström, P. (2018). Differentiation in digital creative industry cluster dynamics: the growth and decline of the Japanese video game software industry. Geografiska Annaler: Series B, Human Geography, 100(3), 263-286.

Friedlander, J. (2016). No Business Like Schmo Business: Reality TV and Fetishistic Inversion. International Journal of Žižek Studies, 1(3).

Gigi Durham, M. and Kellner, D. (2006). Media and Cultural Studies: Keyworks. USA: Blackwel Publishing.

Hall, S. (1997). Representation: Cultural Representations and Signifying Practices. London: Sage.

Heryanto, A. (2017). Historiografi Indonesia yang Rasis, Jakartanicus.
Huggins, M. (2015). The visual in sport history: approaches, methodologies and sources. The International Journal of the History of Sport, 32(15), 1813-1830.

Ida, R. (2014). Metode Penelitian: Studi Media dan Kajian Budaya. Jakarta: Kencan.

Karunianingsih, D. A. (2016). Kamera sebagai Alat Operasi Male Gaze: Analisis Male Gaze dalam Film Horor "Pacar Hantu Perawan. REKAM: Jurnal Fotografi, Televisi, Animasi, 12(1), 19-30.

Luyten, P. (2015). Unholy questions about five central tenets of psychoanalysis that need to be empirically verified. Psychoanalytic Inquiry, 35(sup1), 5-23.

Mannay, D., Staples, E., \& Edwards, V. (2017). Visual methodologies, sand and psychoanalysis: employing creative participatory techniques to explore the educational experiences of mature students and children in care. Visual Studies, 32(4), 345-358.

Mantziari, D. (2018). Sadistic scopophilia in contemporary rape culture: I Spit On Your Grave (2010) and the practice of "media rape." Feminist Media Studies, 18(3), 397-410.

Mulvey, L. (1989a). Visual and Other Pleasures. Heidelberg: Springer.

Mulvey, L. (1989b). Visual Pleasure and Narrative Cinema. In Visual and other pleasures (pp. 14-26). Springer.

Okamoto, T. (2015). Otaku tourism and the anime pilgrimage phenomenon in Japan. In Japan Forum (Vol. 27, pp. 12-36). Taylor \& Francis.

Oktaviani, D. D. (2019). Konsep Fantasi dalam Film. REKAM: Jurnal Fotografi, Televisi, Animasi, 15(2), 125-136.

Rose, G. (2006). Visual Methodologies: an Introduction to Researching with Visual Materials (4th ed.). London: Sage Publications Ltd.

Strinati, D. and Mukhid, A. (2003). Popular Culture: Pengantar Menuju Teori Budaya Populer. Yogyakarta: Jejak.

Suan, S. (2020). Anime's Spatiality: Mediaform, Dislocation, and Globalization. Mechademia: Second Arc, 12(2), 24-44. 
Syawal, S. and H. (2018). Psikoanalisis Sigmund Freud dan Implikasinya dalam Pendidikan Helaluddin Syahrul Syawal. Academia.Edu, March, 1-16.

Tongdhamachart, N. (2015). JAPANESE ANIMATION: THAILAND'S PERSPECTIVE. International Journal of Arts \& Sciences, 8(2), 129.

Yamamura, T. (2019). Cooperation Between Anime Producers and the Japan SelfDefense Force: Creating Fantasy and/or Propaganda? Journal of War \& Culture Studies, 12(1), 8-23.

Yoshioka, S. (2018). Toshio's movie castle: A historical overview of Studio Ghibli's collaboration and promotional strategies. East Asian Journal of Popular Culture, 4(1), 15-29. 
